\title{
HISTORIA DE LA LENGUA E HISTORIA DE LA LENGUA LITERARIA A LA LUZ DEL CATALÁN DE LOS SIGLOS XVI Y XVII ${ }^{1}$
}

Coloma Lleal

Universitat de Barcelona

1. Permítanme unas reflexiones sobre un tema que me parece particularmente sugerente porque plantea una de las cuestiones básicas de la historia de la lengua: la relación entre una lengua y su modalidad literaria. Tema que los latinistas conocen bien: recuerdo cuando el profesor Joan Bastardas insistía en denominar «latín sin más» a la modalidad de latín que estudiábamos en una asignatura titulada Latín vulgar y cuyas características habíamos de deducir a partir de la escasa documentación que nos ha llegado. Y que también conocen quienes desde el campo de la lingüística descriptiva o de la pragmática contraponen unos modelos de lengua «formal» a los de otras variantes.

Los historiadores de la lengua, en cambio, con frecuencia hemos partido casi exclusivamente de un solo registro. A menudo, porque los hechos nos han obligado a ello: solo disponemos de los testimonios escritos que, inevitablemente, están dominados por las leyes del registro culto. Pero también a veces

1 El presente artículo es una revisión de la conferencia pronunciada en el Seminario de Historia de la Lengua Española «Unidad y diversidad en el español del Siglo de Oro» organizado por la Fundación Duques de Soria, Soria, 20-24 de julio de 1998. 
porque era nuestra única posibilidad de poner un poco de orden en nuestro desconocimiento de la lengua de épocas pasadas. Todos hemos explicado alguna vez cuáles eran las características fonológicas, sintácticas o morfológicas del castellano medieval, deducidas básicamente de las obras alfonsíes. Pero cualquier incursión en textos de otras procedencias nos sume en un mar de perplejidades. En el mejor de los casos hablamos de inexperiencia del escriba, de desconocimiento de la norma culta o de la afloración de misteriosas variantes regionales. La sociolingüística o el estudio de la variación lingüística suelen quedar incomprensiblemente muy lejos de nuestro análisis.

Esta identificación de lengua con lengua literaria y, subsidiariamente, de historia de la lengua con historia de la literatura, puede ser particularmente empobrecedora cuando, como ocurre en el caso del catalán moderno, carecemos de testimonios literarios a partir de los cuales estudiar amplios periodos de la historia de la lengua, hasta el punto de que ha sido posible hablar de una postración o incluso desaparición, primero, y de una creación o invención posterior de la lengua catalana. Y todavía hoy siguen siendo escasísimos los estudios sobre el catalán de los siglos XVI y XVII ${ }^{2}$.

2. Recordemos brevemente los datos: el periodo que, no de forma casual ni gratuita, es conocido como Siglo de Oro de la literatura española coincide con la época de mayor decadencia de las letras catalanas. Ni un solo autor capaz de escribir unas páginas memorables durante más de doscientos años. $\mathrm{Y}$, sin embargo, si desde el campo de la literatura analizamos el periodo inmediatamente precedente, no hay nada que vaticine el desastre posterior. Ni ausencia de tradición literaria ni falta de estímulos innovadores ${ }^{3}$. Pocos años antes Ausias March, traducido repetidamente al castellano en el siglo XVI, había modernizado la poesía apartándola definitivamente de la imitación servil y anacrónica trovadoresca, y Joanot Martorell, elogiado por Cervantes, había perfeccionado la técnica del relato novelesco. Y cito solo dos casos paradigmáticos. Poco después, súbitamente, el desierto literario. Tras el humanismo, tempranamente introducido e intensamente arraigado, solo hallamos una profunda decadencia de la cultura literaria.

2 CAHNER, M. (1980): «Llengua i societat en el pas del segle XV al XVI. Contribució a l'estudi de la penetració del castellà als Països Catalans», en Acres del V Colloqui Internacional de Llengua i Literatura Catalanes, Barcelona, pp. 183-255. NADAL, J.M. (1989): «Problemes lingüístics en els segles XVI i XVII", en Segon Congrés Internacional de la Llengua Catalana, VIII. 7. València, Institut de Filologia Valenciana. pp. 53-66. SANCHIS GUARNER, M. (1963): Els valencians i la llengua autòctona durant els segles XVI. XVII i XV $/ 1 /$. València. Inst. Alfons el Magnànim.

${ }^{3}$ BADIA, L. (1993): Tradició i modernitat als segles XIV $i$ XV. Estudis de cultura literària $i$ lectures d'Ausiàs March. València/Barcelona, Institut de Filologia Valenciana/Pub. Abadia de Montserrat. 
Se ha apuntado como explicación posible el proceso castellanizador iniciado con el advenimiento de la dinastía Trastámara en tiempos de Fernando I y consumado-con la unión dinástica con la corona castellana en tiempos de Fernando II. Sin embargo, habría que precisar el alcance de este proceso para ver en qué medida afectó a la competencia lingüística de los tres grupos sociales básicos: la nobleza, la burguesía urbana y el pueblo.

Una primera precisión, sin la cual difícilmente podríamos entender la situación posterior, tiene que ver con el carácter exclusivamente cortesano de la producción literaria de los siglos XIV y XV. El papel de los escribanos, secretarios, protonotarios y, en general, de los miembros de la Cancillería real en la configuración de la norma culta del catalán fue fundamental. Y, dada la difusión de la abundante correspondencia emanada de la Cancillería ${ }^{4}$, la modalidad lingüística propia de este registro cancilleresco se extendió rápidamente y afectó a amplios sectores de la población de la Corona de Aragón. En otro lugar ${ }^{5}$ me referí ya a este proceso de difusión de las innovaciones linguísticas prerrenacentistas. Pero aquí quisiera destacar la pertenencia a este ambiente cortesano y cancilleresco de todos los autores literarios de la época. Como señala Martí de Riquer ${ }^{6}$, tanto Bernat Metge y Andreu Febrer, secretarios reales, como Ausias March, halconero real, o Arnau de Vilanova y Jacme Roig, médicos de la corte, o Vicente Ferrer y Francesc Eiximenis, confesores y consejeros reales, o Bernat Hug de Rocabertí y Pere Torroella, caballeros y cortesanos vinculados a Juan II, o Felip de Malla, embajador, e incluso Isabel de Villena, hija de don Enrique de Villena y educada en la corte de la reina regente doña María, todos cuantos escriben pertenecen siempre a los círculos nobiliarios o cancillerescos que se mueven en torno a los soberanos ${ }^{7}$. Precisamente por ello, las vicisitudes de la corte tuvieron efectos decisivos sobre la lengua literaria.

En segundo lugar, hay que recordar el bilingüismo de la Cancillería en unos reinos que, como se ha dicho repetidamente, tenían un carácter confederado. Aparte del latín, el catalán y el aragonés actuaban como lo que, en terminología moderna, podríamos denominar «lenguas oficiales» de la Cancillería. Un somero repaso de cualquiera de los registros de Cancillería del siglo $\mathrm{XV}$ permite observar

${ }^{4}$ Lleal, C. (1997): El castellano del siglo XV en la Corona de Aragón, Zaragoza, Institución «Fernando el Católico».

"LlEal, C. (1995): «El secretario, el nuncio y la difusión del latinismo en el siglo XV», Lletres Asturianes, 56, pp. 19-34.

- Riquer, M. DE (1964): Història de la Literatura Catalana, vols. III y IV, Barcelona, Ariel, 1985.

7 Venderell de Millás, F. (1933): La corte literaria de Alfonso V de Aragón, Madrid. 
la convivencia de las tres lenguas, así como el elevado número de misivas que presentan doble redacción, según vayan dirigidas al batlle de una localidad catalana, valenciana o mallorquina o bien a un bayle aragonés. Pero aún con mayor frecuencia encontramos una sola redacción en aragonés acompañada de anotaciones del tipo «Alia similis fuit expedita mutatis mutandis sub eadem data sigillo adque mandato directa infrascriptis in ydiomate cathalano" ${ }^{8}$ o viceversa. Observamos, pues, que durante la primera mitad del siglo XV aparecen redactados en aragonés los textos remitidos a funcionarios de Aragón, o la correspondencia mantenida con Castilla, Navarra, Portugal y algunos estados del norte de África, mientras que los textos dirigidos a los reinos de habla catalana están siempre redactados en catalán. Incluso las cartas intercambiadas entre Alfonso V y su esposa, la reina regente doña María de Castilla, están escritas, mayoritariamente, en catalán ${ }^{9}$. Los secretarios reales debían, pues, ser igualmente competentes en las dos lenguas. $\mathrm{Y}$ en la corte convivían curiales, nobles y caballeros de los distintos reinos de la Corona, para quienes el bilingüismo catalano-aragonés tenía que ser habitual. Se trata de un fenómeno sociolinguístico resultante de las características de la Corona de Aragón como confederación creada tras la muerte del rey Ramiro II y que se manifiesta abiertamente en toda la documentación cancilleresca desde mediados del siglo XIII ${ }^{10}$.

En tercer lugar, a lo largo del siglo XV observamos cómo los textos cancillerescos redactados en aragonés van abandonando progresivamente los rasgos linguísticos de esta modalidad para aproximarse al castellano. En esa confluencia intervinieron, claro está, factores estructurales, pero es posible que el hecho de que los secretarios aragoneses de Fernando II ${ }^{11}$ actuasen también en los asuntos de Castilla contribuyera poderosamente a la castellanización de la modalidad cancilleresca utilizada por ellos ${ }^{12}$. Por consiguiente, a fines del

* ACA, Reg. Cancill. 2575, fol. 9v, en Lleal, C. (1997).

* Habría que aclarar que se trata siempre de cartas relacionadas con el gobierno de Valencia o de Cataluña, no de misivas de carácter personal. Son pues textos redactados por los miembros de la Cancillería por orden del monarca, no de textos escritos de su mano. En claro contraste con las cartas de Juan II a su esposa, doña Juana Enríquez, que tienen siempre un carácter muy personal, incluso claramente afectivo, y que por ello están escritas en castellano que es su lengua familiar. Véase COLÓN, G. (1989): «El aragonés cancilleresco: sociología de un idioma», en El español y el catalán, juntos y en contraste, Barcelona, Ariel, pp. 240.

i1 Véase Colón, G. (1989). pp. 237-270.

1 Hugo de Urriés, Juan de Coloma, Gaspar de Ariño, Francisco Vidal. Luis González o Miguel Pérez de Almazán.

12 ENguita, J.M. y ARNAL, M.L. (1996): «Llámala Aragón ffenojom, en Fernando /l de Ara. gón. el rey Católico, Zaragoza, Institución «Fernando el Católico», pp. 411-427. FRAGO, J.A. (1991.a): «Conflicto de normas lingüísticas en el proceso castellanizador de Aragón», en Actas del I Curso de Geografía Lingüística de Aragón, Zaragoza, Institución "Fernando el Católico». 
siglo XV los secretarios reales eran capaces de redactar, indistintamente, un documento en catalán o en castellano, con algún aragonesismo esporádico $-\mathrm{y}$, repito, también en latín, pero no es ahora este el tema que nos ocupa-. Y, recíprocamente, los altos funcionarios aragoneses podían entender un documento en catalán: aunque lo normal era que la documentación enviada a los funcionarios aragoneses estuviera redactada en castellano, no era imposible el uso del catalán. El bilingüismo castellano-catalán de la corte y de los ambientes próximos a la administración acabó siendo la norma general ${ }^{13}$. La novedad, respecto de épocas anteriores, consiste en la substitución del aragonés por el castellano, no en el carácter bilingüe de la corte aragonesa. En otros términos, el uso del castellano por parte de los cortesanos catalanes no depende directamente y de forma casi mecánica del origen del monarca, único factor, en cambio, sobre el que se suele insistir para explicar el proceso de castellanización de los ambientes cultos catalanes. Porque la lengua familiar del monarca -o de su cónyuge - ha ejercido una influencia muy relativa en la evolución de la lengua de un país. Suponer lo contrario equivaldría, en palabras de Riquer ${ }^{14}$, a considerar que necesariamente se tendría que haber producido una germanización de las letras hispanas con el advenimiento de los Habsburgo, cuando, precisamente, este fue el periodo de su máximo esplendor.

3. En este contexto, no es de extrañar el uso esporádico del castellano por parte de los autores cortesanos catalanes del XV, así como el más esporádico todavía uso del catalán por parte de autores aragoneses afincados más o menos temporalmente en tierras de habla catalana. Así, Joan de Masdovelles, Pere Torroella, Francesc Moner, Francesc Carroç o Bernat de Fenollar escribieron en castellano algunas de sus composiciones ${ }^{15}$, como también lo hizo Juan de Flo-

pp. 105-126. FRAGO, J.A. (1991.b): «Determinación sociolingüística en la castellanización del Valle del Ebro», en I Curso sobre Lengua y Literatura en Aragón, Zaragoza. Institución «Fernando el Católico", pp. 115-131.

13 Recuérdese, a este respecto, el debate epistolar mantenido a mediados de este siglo entre Roís de Corella y el príncipe de Viana: éste escribe siempre en castellano, pero CORELLA le responde en catalán. Y no se trata de un caso aislado. Véase Carbonell, J. (1955): «Sobre la correspondència literària entre Roís de Corella i el príncep de Viana», Estudis Romànics, V. pp. 127-139.

14 Riquer, M. DE (1964), IV, pp. 436.

is CAtedra, P.M. (1983): Poemas castellanos de cancioneros bilingües, Exeter Hispanic Texts, XXXIV. Cocozzella, P. (1987): «Pere Torroella i Francesc Moner: aspectes del bilingüisme literari (catalano-castellà) a la segona meitat del segle XV», Llengua \& Literatura, 2, pp. 155 172. Pedro Bach y Rira. Ph.D. (1930): The Works of Pere Torroeila, Nueva York, Instituto de las Españas. Reyes Tudela, J.E. (1980): Las obras de Francesch Carros Pardo de la Casta, autor bilingüe valenciano del siglo XV: edición, estudio y notas, tesis doctoral, State University of New York at Binghamton. 
res, autor de novelas de inspiración boccaciana. Un conocido ejemplo del caso inverso lo tenemos en don Enrique de Villena que en 1417 escribió en catalán Los Dotze Treballs d' Hèrcules, traducido posteriormente por él mismo al castellano ${ }^{16}$, y participó en los Juegos Florales de Barcelona, de los que dejó una descripción detallada en su Arte de trovar. Y también escribieron en catalán el aragonés Pedro de Santa Fe o el navarro Francisco de Amezcua. Todos ellos vinculados a la corte aragonesa.

Por otra parte, casi todas las obras que estos cortesanos bilingües escribían en castellano eran de carácter poético. Y era muy reciente todavía el recuerdo de un modelo de lengua artificioso para las composiciones en verso. Ausias March se había apartado de él, pero todavía a mediados del XV encontramos un buen número de composiciones fieles a esos modelos de corte trovadoresco. Quienes escribían poesía tenían que plantearse previamente la elección de una modalidad de lengua. Y precisamente en este momento de crisis de la lengua poética, se introdujeron nuevos modelos italianizantes, fruto de las intensas relaciones con el reino de Nápoles. Porque, aparte de los nobles y miembros de la Cancillería que se establecieron en Nápoles con Alfonso $\mathrm{V}$, muchos de los que permanecieron en la corte barcelonesa o valenciana tuvieron frecuentes contactos con la corte napolitana y con todas las innovaciones culturales y literarias que se estaban dando en ella. No debe pues sorprendernos que en poesía se produjera una substitución lingưística del catalán, más o menos teñido de provenzal, por el castellano o por el italiano. La innovación en la poesía no suponía solamente la renovación del metro, de la rima y de los temas, sino que afectaba también al plano lingüístico: Romeu Llull o Narcís Vinyoles utilizaron las tres lenguas para componer sus obras poéticas. El carácter elitista y, en cierta medida, lúdico de estas composiciones explican claramente el juego lingüístico. El Jardinet d'orats, conservado en la Biblioteca Universitaria de Barcelona, el Cançoner de l'Ateneu o el Cancionero de Stuñiga son una buena muestra de este uso del castellano por parte de los autores catalanes de mediados del siglo XV. Los contados intentos posteriores de escribir poesía en catalán chocaron con este dilema linguístico: el catalán literario, asociado al «llemosí», sería visto como una modalidad artificiosa, muy alejada de la lengua viva, posiblemente tanto como lo era todavía para ellos el castellano ${ }^{17}$.

16 Edición de M. Morreale, Madrid, 1958

17 FUSTER, J. (1984): «Notes sobre el 'llemosí" a la València del segle XVI», en Homenatge a Joan Fuster, Girona. NADAL. J.M. (1983): «Usar de llenguatge artificiós» en el segle XVI: ideologia lingüística i llengua literària”, en Actes del V Congrés de Llengua i Literatura Catalanes. Pub. Abadia de Montserrat, pp. 89-125. 
4. Junto a estos factores culturales, estrechamente vinculados con la aparición de una nueva mentalidad renacentista que hermanaba a la intelectualidad en su búsqueda de nuevos modelos y en su actitud de preferencia por lo general y rechazo de lo particular - que necesariamente tendrían que plasmarse en unas opciones lingüísticas - la situación política de fines del siglo XV experimentó un cambio notable. Tras la guerra civil, en tiempos de Juan II, numerosos infanzones e hidalgos aragoneses fueron recompensados por su lealtad al monarca con concesiones territoriales y de dominio en tierras de habla catalana. El uso del castellano trascendió los límites de la corte y se extendió al conjunto de la nobleza. Pero el cambio radical se produjo en tiempos de Fernando II. Después de la unión dinástica, la corte aragonesa (el Consejo Real o Consejo de Aragón), que seguía siendo itinerante, se estableció siempre en tierras castellanas, donde convivían los nobles y curiales catalano-aragoneses con los castellanos. Y, mientras los cortesanos de la Corona de Aragón, independientemente de su procedencia, entendían el catalán y el castellano, no era este el caso de los cortesanos de Castilla. Por ello, el castellano acabó siendo su única lengua de comunicación.

La correspondencia de Estefanía de Requesens, esposa de Juan de Zúñiga, camarlengo de Carlos I y preceptor del infante Felipe, nos proporciona interesantes detalles de este proceso. En las cartas que escribe a su madre -en catalán-, alude al aprendizaje del castellano por parte de su hijo o de sus criados: «Lloyset (...) continua son estudi i parla lo castellà molt bonico y (...) ab son pare tenen conversació molt sovint y (...) diu-li «no está bien informado vuestra merced" y altres voltes "eso no viene al caso", y mil altres coses de $q u \grave{e}$ gustam raonablement». A su paje «Don Juan, mon senyor, li fa aprendre d'escriure en castellà», mientras que una de sus criadas no consigue dominar la lengua de la corte: «may l'a poguda apendre, que parla que són rialles». Por ello, don Juan de Zúñiga insiste en que busque nueva criada y que «la prenga castellana (...) perquè sàpia la manera y la llengua de ací» ${ }^{18}$.

La conjunción de estos factores - establecimiento de la mayor parte de la nobleza catalana en tierras de la corona de Castilla, con la consiguiente adopción del castellano, carácter nobiliario de la literatura, asociación entre catalán y «llemosí», por una parte, y modernización y castellano, por otra-, junto con la admiración que despertaba en ellos la floreciente literatura castellana, nos permite explicar la progresiva desaparición de una literatura en lengua catala-

18 CAHNer, M. (1977): Epistolari del Renaixement, 2 vols., València, Albatros. GuISADo, M. (1987): Requesens i Roís de Liori, Estefania de: Cartes íntimes d' una dama catalana del segle XVI, Barcelona, La Sal, cartas del 11-3-1534 pp. 23-29: 24-11-1534, pp. 45-52 y 5-12-1535, pp. 191194. 
na. Como decía al principio, las letras catalanas entran en un periodo de profunda postración. Porque todas las figuras de cierto nivel --Juan Boscán, Juan Timoneda, Gil Polo, Guillén de Castro- escriben casi exclusivamente en castellano —o en latín, como Juan Luis Vives-.

5. Hasta aquí los datos que explican la desaparición de la literatura catalana en relación con la castellanización de la corte. Pero un historiador de la lengua no puede limitarse a ellos.

En primer lugar, hemos de preguntarnos cuál era la situación lingüística de los miembros de las otras capas sociales. Y esto solo lo podemos conocer a través de textos de muy escaso valor literario, y de ahí el poco interés que han suscitado. Sin embargo, tienen un extraordinario valor lingüístico porque nos permiten constatar en qué medida la nueva actitud frente a la lengua se extiende fuera de los círculos cortesanos.

En 1479 un notario barcelonés, Pere Miquel Carbonell, escribe en castellano una carta al secretario real Gaspar de Ariño, aragonés, en la que le pide disculpas por su insuficiente conocimiento de la lengua: «si algunos motes son a la presente por mi mal escritos, por no tenir la lengua castellana, v.s. no se maravilla car es la primera que mai fizo en esta lengua e dellihero continuar en ella por me abilitar e responder a v.s. por la mesma manera." ${ }^{19}$. Posiblemente, conscientes de lo poco que «se habilitaban», algunos miembros de la alta burguesía catalana intentaron mejorar la formación lingüística de sus hijos con la ayuda de preceptores castellanos. Tal vez con la esperanza de que algún día llegaran a convertirse en miembros de esa clase diferenciada, linguística y socialmente, de los cortesanos renacentistas, en la que empezaban a predominar los componentes de nuevas capas sociales.

Si analizamos la documentación cancilleresca de fines del siglo XV y principios del XVI, aparentemente no se han producido grandes cambios: los textos administrativos del área lingüística catalana siguen redactándose en catalán - y lo siguieron haciendo hasta fines del XVIII-, pero las cartas reales dirigidas a las autoridades catalanas a menudo se escribían en castellano, situación muy distinta de la de periodos anteriores. Y esto no solo se daba cuando el rey se dirigía a los lugartenientes generales de Cataluña - su primo don Enrique de Aragón y Pimentel, que había pasado su infancia en Castilla, o a su sobrino don Juan de Aragón, casi de su misma edad con el que se había educado - sino incluso cuando se dirigía a los consejeros o a los diputados de la ciudad de Barcelona, es decir, a miembros de la alta burgue-

19 Citado por Cahner, M. (1980), pág. 199. 
sía urbana ${ }^{20}$. Y su sucesor, Carlos I utilizó casi exclusivamente el castellano ${ }^{21}$. El cambio de actitud por parte de los monarcas es evidente.

No olvidemos además que aunque las instituciones catalanas siguieron vigentes durante los siglos XVI y XVII, perdieron progresivamente sus atribuciones en la jurisdicción civil y criminal, al tiempo que las cortes catalanas eran raramente convocadas por los monarcas ${ }^{22}$. El papel regulador que hasta el siglo XV había desempeñado la lengua cancilleresca, convertida en modelo de la lengua literaria, desapareció súbitamente como consecuencia del divorcio entre lengua administrativa -catalana - y lengua literaria - castellana-, dejando a las modalidades de lengua culta sin un modelo unitario de referencia. Ante la ausencia de norma, quienes escribían en catalán reflejaban en sus obras las características de su habla. El proceso de dialectalización y de afloración de rasgos de la lengua familiar era inevitable.

6. Otra interesante muestra del cambio en la valoración de la lengua la tenemos en el teatro. Como bien sabemos, el teatro renacentista se secularizó, se introdujo en la corte y ambientes nobiliarios y, finalmente, consiguió difundirse a un público más amplio a través de los primeros corrales, particularmente concurridos en Valencia ${ }^{23}$, donde el de L'Olivera fue la principal puerta de entrada del teatro italianizante. Difícilmente podemos tomar al pie de la letra los datos lingüísticos que nos brinda el teatro, porque posiblemente tengan mucho de ficción literaria —recuérdese el ejemplo del «sayagués»- pero la norma del decoro exigía, de acuerdo con los principios expresados por Torres Naharro, que no solo en las obras a noticia sino también en aquellas que eran a fantasía los personajes tuviesen «color de verdad aunque no lo sean» ${ }^{24}$. Por ello, los diálogos bilinguies que encontramos en algunas obras teatrales que seguían la moda iniciada por Torres Naharro en Serafina, pueden permitirnos una aproximación a la situación linguiística de la época. Así, en La vesita, de Juan Fernández de

20 ACA, Reg. Canc. 3553, 3569 y 3666, reproducidos en Lleal (1997), documentos 172 , $173,175,176,177,178,179,180,182$ y 200.

21 VOLTES Bou, P. (1958): Cartas del emperador Carlos I a la ciudad de Barcelona, Universidad de Barcelona.

22 Fernando II solo las convocó cinco veces; Carlos I, seis; Felipe II, solo dos; Felipe III y Felipe IV, una vez cada uno; y Carlos II no lo hizo nunca. Véase LlEAL, C. (1992): Breu història de la llengua catalana, Barcelona, Barcanova, pp. 107-132.

${ }^{23}$ Mérimé, H. (1913): L'Art dramatique d Valencia, depuis les origines jusqu'au commencement du XVIle siècle, Toulouse, Bibliothèque Méridionale.

24 Torres Naharro, B. DE (1517): Propaladia, ed. de J.E. Gillet, Pensilvania, B. Mawr, 1943, I, p. 142. 
Heredia ${ }^{25}$, representada en la corte de Germana de Foix hacia 1525 y que nos ofrece interesantes diálogos entre las damas valencianas y las criadas y los caballeros, observamos cómo entre ellas las damas utilizan siempre el catalán, y también lo hacen cuando se dirigen a sus criadas, a pesar de que éstas son castellanas, pero cambian sistemáticamente de registro cuando se dirigen a los caballeros castellanos. Interesante dato sociolingüístico que explica la adopción del castellano no solo como consecuencia de la no reciprocidad en el conocimiento de las dos lenguas sino, sobre todo, por el mayor prestigio del castellano entre la nobleza.

Pero sobre todo, tal vez lo más significativo sea que este teatro «realista» solo se representaba en los ambientes áulicos de la pequeña corte valenciana, a menudo interpretado por los propios cortesanos, mientras que en los hostales, las plazas y los corrales de comedias las preferencias se inclinaban claramente por el teatro representado por las compañías ambulantes castellanas ${ }^{26}$. Es evidente, en este caso, que lo que realmente emocionaba al público era lo que podríamos denominar la "puesta en escena" de aspecto casi circense de las compañías profesionales. Pero, indirectamente, sus actuaciones fueron acostumbrándolo a familiarizarse con el castellano.

7. Sería falso, sin embargo, deducir de ello que el uso del castellano se había generalizado. Entre la burguesía, el catalán seguía siendo la lengua habitual, como parece confirmarlo el testimonio de los numerosos dietarios, tanto los de las corporaciones como, sobre todo, los particulares. Entre los primeros, destacan el Dietari de la Generalitat ${ }^{27}$, en el que figuran los acontecimientos de carácter militar, político, religioso o ciudadano más significativos de los siglos XV al XVIII; el Llibre de les solemnitats de Barcelona ${ }^{28}$, escrito entre 1424 y 1719 , donde se describe lo que podríamos denominar «el protocolo» de las celebraciones importantes en que intervenían los representantes de la ciudad de Barcelona; el Manual de novells ardits ${ }^{29}$, dietario del racional donde se

25. Las obras de don Juan Fernández de Heredia, assí temporales como espirituales (Valencia, 1562), edición de R. FERREREs, Madrid, Clásicos castellanos, 1955. Una situación similar la encontramos en El Cortesano, de Lluís DEL MiLA (1561).

26 Fuster, J. (1976): La decadència al País Valencià, Barcelona, Curial, p. 76.

27 Compuesto por 109 volúmenes, de 1411 a 1711 , y 40 volúmenes con borradores y anotaciones de 1611 a 1713, ha sido editado parcialmente por M. Mrruà, Barcelona, Associació de Bibliòfils, y por el Archivo de la Corona de Aragón ( Colección de Documentos Inéditos»).

${ }_{28}$ Conservado en el Archivo Histórico de la Ciudad y publicado por A. DURAN i SANPERE y J. SANABrE, Barcelona, Institució Patxot, 1930-47.

${ }^{29}$ Conocido también como Dietari de l'antic consell barceloní, está formado por 49 volúmenes. Su edición fue iniciada en 1892 por F. Carreras Candi y F. Schwarz y continuada en 1965 bajo la dirección de P. Voltes. 
registran todas las noticias (ardits) que justifican algún gasto, y que comprende el periodo que va desde fines del siglo XIV hasta mediados del XIX, y el Llibre de memòries de la ciudad de Valencia ${ }^{30}$, que abarca de 1308 hasta 1644. Entre los particulares destacan el Dietari ${ }^{31}$ del barcelonés Jaume Safont, del siglo XV, el del valenciano Jeroni Sòria ${ }^{32}$, las Memòries del también valenciano Gaspar Antist y el Llibre d'algunes coses assenyalades del barcelonés Pere Joan Comes ${ }^{33}$, todos ellos del siglo XVI, o el Dietari del barcelonés Jeroni Pujades ${ }^{34}$ y el del valenciano Joan Porcar ${ }^{35}$, del siglo XVII. A partir de estos textos, cuyas últimas manifestaciones llegan hasta el siglo XIX con los numerosos Llibres de familia ${ }^{36}$ o el Calaix de sastre del barón de Maldá ${ }^{37}$, podemos deducir que, mientras en Cataluña la lengua en que se expresaba la burguesía urbana seguía siendo el catalán, en Valencia, en cambio, el uso del catalán escrito - $-\mathrm{y}$ en buena medida, también hablado- desapareció de estos sectores a mediados del siglo XVII ${ }^{38}$.

En cualquier caso, aunque la lengua familiar siguiera siendo la catalana, los ambientes cultivados dejaron de ser monolingües. La difusión de la im-

${ }^{30}$ Llibre de memòries de diversos successos e fets memorables e de coses senyalades de la ciutat e Regne de València, ed. de S. Carreres Zacarés, Valencia, Acción Bibliográfica Valenciana. 1930-35, 2 vols.

${ }_{31}$ Dietari de les torbacions del temps del rei don Joan que en Catalunya foren, conocido también como Dietari o llibre de jornades. Contiene un cronicón del periodo 1238-1409, una relación de efemérides de los años 1411 y 1412 y, finalmente, el dietario propiamente dicho que comprende de 1414 a 1484 .

32 Dietari de Jeroni Sòria, ed. de Francisco Momblanch, Valencia, Acción Bibliográfica Valenciana, 1960.

${ }^{33}$ Contiene numerosos datos procedentes del Llibre de solemnitats i del Manual de novells ardits, así como la copia de numerosos documentos municipales secretos, por cuya publicación fue procesado.

${ }_{34}$ Publicado por J. Casas Homs: Dietari de Jeroni Pujades, Barcelona, Fundació Vives Casajoana, 1975-76.

35 Pere Joan Porcar, Dietari, 1589-1628 (Antologia), ed. de Ferran Garcia, València, Biblioteca d'Autors Valencians, 1983.

36 CiCCHETI, A. (1993): «Le memorie familiare tra archivo privato e sistema letterario: percorsi testuali», Annali Scuola Normale, XXIII-2, pp. 701-740. ESCARTi, V.J. (1990): «Unes consideracions sobre la dietarística valenciana del segle XVII», Caplletra, 9, pp. 119-128. LLEAL, C. (1993): El «Llibre de polítigas» de Janet Lleal, Barcelona, PPU. MORAN OCERINJÀUREGUI, J. (1987): «Un document familiar català del segle XVIII», Llengua \& Literatura, 2, pp. 295-319. PANDIMIGLIO, L. (1987): «Ricordanza e libro di famiglia. Il manifestarsi di una nuova fonte», Lettere ltaliane, XXXIX, pp. 3-19.

${ }^{37}$ AMAT I DE CORTADA, BARÓ DE MALDA, R. D': Calaix de sastre, ed. de R. Boixareu, Barcelona, Curial, 1987-88.

${ }^{38}$ Batlle, C. y RAFAnell, A. (1989): «Algunes consideracions sociolingüístiques sobre els dietaris de Porcar, Vic i Soria», en Segon Congrés Internacional de la Llengua Catalana, VIII, 7 , València, Institut de Filologia Valenciana, pp. 259-288. 
prenta, por una parte, y la reforma religiosa, por otra, supusieron una progresiva familiarización con el uso, al menos pasivo, del castellano.

Analicemos brevemente los datos que conocemos sobre la producción editorial de Valencia ${ }^{39}$. Mientras en el primer cuarto de siglo de la historia de la imprenta (de 1473 a 1506) la lengua de las obras impresas en Valencia era el catalán o el latín, con una escasa presencia del castellano, a partir de 1510 el latín mantuvo una situación similar —salvo durante el periodo de las Germanías-, pero la situación se invirtió para el uso del catalán o del castellano.

\begin{tabular}{cccc}
\hline & latín & catalán & castellano: \\
\hline $1473-1510$ & $47,6 \%$ & $47,5 \%$ & $5,0 \%$ \\
\hline $1510-1520$ & $36,2 \%$ & $26,4 \%$ & $37,4 \%$ \\
\hline $1521-1524$ & $8,4 \%$ & $25,0 \%$ & $66,6 \%$ \\
\hline $1525-1544$ & $32,4 \%$ & $13,2 \%$ & $54,4 \%$ \\
\hline $1545-1572$ & $53,0 \%$ & $8,6 \%$ & $38,4 \%$ \\
\hline
\end{tabular}

Aunque habría que matizar el alcance de estas cifras, porque parten exclusivamente de los titulos de las obras y no tienen en cuenta la presencia en ellas de fragmentos, más o menos extensos, en otras lenguas -como veremos más adelante a propósito de los ordinarios o rituales-, no parece aventurado concluir que a fines del siglo de Oro una persona medianamente instruida era capaz de entender un texto en castellano, porque la mayor parte de la producción literaria en lengua vulgar que se le ofrecía en las librerías estaba en esta lengua.

8. Pero incluso el pueblo no letrado estuvo en contacto con el castellano. Por una parte, como ya hemos visto, a través de las representaciones teatrales. Por otra, tenemos el testimonio de la difusión del romancero castellano del que se han conservado numerosas versiones que prueban la popularidad que alcanzó. El análisis de estos textos muestra que, a diferencia de la transmisión de las canciones francesas que encontramos en los siglos XIV y XV, siempre tradu-

39 FERRANDO, A. y V.J. ESCARTf (1998): «Impremta i vida literària a València en el pas del segle XV al XVI», en G. Colón y L. GIMENo (eds.): Cultura i humanisme en les lletres hispàniques (s. XV-XVI), vol LXXIV del Boletín de la Sociedad Castellonense de Cultura, Castellón. BERGER, PH. (1987): Libro y lectura en la Valencia del Renacimiento, 2 vols, Valencia, IVEI, cap. IX, y BERGER, PH. (1989): «La crisi del català al País Valencià durant el segle XVI», en Segon Congrés Internacional de la Llengua Catalana, VIII, 7, València, Institut de Filologia Valenciana, pp. 305-311. 
cidas al catalán, el romancero castellano se transmitió generalmente sin traducir, aunque a menudo intensamente deturpado. El carácter bilingüe de muchas de estas composiciones es un fiel reflejo del proceso de familiarización parcial con el uso del castellano.

El romance de santa Catalina, recogido por Milá y Fontanals, ilustra bien esta situación lingüística ${ }^{40}$ :

Aquí dalt en estos montes y en tierras muy regaladas

n' hi nasqué una criatura que Catalina se llama

su padre es un rey moro, su madre una renegada

la varen donar a criar a una dida cristiana.

La dida, la bona dida, la doctrina li ensenyava.

El dia que ho va saber su padre l'atormentava.

que en deixés la llei de Cristo, que en prengués la luterana ${ }^{41}$.

Ella dice que no puede, que a un Dios estava donada.

Son pare manda los criados, para más atormentarla,

que guarnesquien una rueda de cuchillos y navajas.

Asimismo, la reforma de las órdenes religiosas, junto con el papel desempeñado por la nueva Inquisición ${ }^{42}$. supuso la presencia de numerosos clérigos castellanos al frente de las principales sedes episcopales y de los monasterios y conventos más influyentes, la aparición de importante documentación castellana en los tribunales eclesiásticos y la publicación de obras divulgadoras de la nueva espiritualidad, también en castellano. Precisamente las primeras publicaciones en castellano que salieron de la imprenta del monasterio de Montserrat fueron dos manuales espirituales, escritos por el nuevo abad García Ximénez de Cisneros, primo del cardenal Cisneros ${ }^{43}$. Pero este papel castellanizador de algunos sectores de la iglesia solo afectó a los clérigos directamente relacionados con la jerarquía eclesiástica o a los letrados. Mientras

40 Massot i Muntaner, J. (1961): «El romancero tradicional español en Mallorca», Revista de Dialectología y Tradiciones Populares, XVII, pp. 157-173. MLLÁ y Fontanals, M. (1853): Romancerillo catalán, Barcelona, p. 26. RIQUER, M. DE (1964): Història de la Literatura Catalana, 4, Barcelona, Ariel, 1985, pp. 412-433.

${ }^{41}$ Obsérvese el curioso anacronismo que actualiza las preocupaciones religiosas.

42 AlCalá, Á. y otros. (1984): Inquisición española y mentalidad inquisitorial. Ponencias del Simposio Internacional sobre Inquisición, Barcelona, Ariel. VENTURA, J. (1978): Inquisició espanyola i cultura rencixtentista al Pais Valencia, València, Tres i Quatre.

${ }^{43}$ Directorio de las horas canónicas y Exercitatorio de la vida espiritual, editadas el año 1500. Véase Colombàs, G.M. (1955): Un reformador benedictino en tiempos de los Reyes Católicos, Montserrat, pp. 90-91 y 133-134. 
que el pueblo siguió usando y oyendo el catalán en la mayoría de las celebraciones litúrgicas.

En efecto, si analizamos los libros litúrgicos de los siglos XVI y XVII, todos ellos escritos en latín, observamos la frecuente intercalación de fórmulas en catalán en la exhortación a los padrinos en el ritual del bautismo: «vosaltres, padrí e padrina sou tenguts...», en las preguntas a los contrayentes, la exhortación y la fórmula del casamiento, en las preces dominicales, la comunión a los enfermos o en el ritual de la extremaunción. Y con frecuencia, incluso las rúbricas están en catalán: «de com se ha de haver lo confessor ab lo penitent..." En todos ellos se insiste en la necesidad de dirigirse a los creyentes en catalán: «en nostre llengua materna, perque facilment tots lo entengan (...) apres del offertori, ensenyaran al poble la doctrina christiana tota en llengua cathalana (...) diga en llengue cathalana, yo pecador me confes à Deu (...) quan no hi haura sermo, ensenyara breument al poble la doctrina christiana en llengua vulgar, del modo seguent...» ${ }^{44}$.

La predicación y el teatro religioso - milagros, misterios, pasiones, consuetes-, por una parte, y la poesía popular, a menudo irreverente y obscena, por otra, constituyen la única manifestación en lengua catalana a que tenía acceso el pueblo. Pero mientras los sermones dominicales de las parroquias se hacían en catalán, en las fiestas solemnes y, sobre todo, en las catedrales y grandes monasterios, los obispos, abades y canónigos, a menudo procedentes de Castilla, propugnaban el uso del castellano: pronto la oratoria barroca se impuso en el púlpito y numerosos clérigos poco doctos intentaron remedarla. Las dificultades de comprensión por parte de algunos fieles no eran óbice para ello, porque no se trataba tanto de convencer como de causar admiración.

Sin embargo, este conocimiento del español, por superficial que fuera, solo se daba en los ambientes más cultivados de las grandes ciudades, mientras que la población rural siguió siendo prácticamente monolingüe. Pere Gil, en la introducción a la traducción catalana del Kempis lo expresa claramente: «Alguns per ventura judicaran que en aquest temps no era necessari imprimir-se lo present llibre en esta llengua, puis la castellana, dita ja espanyola, és casi universalment entesa. Pero com se veja $i$ toque ab les mans que, exceptades algunes poques ciutats (...) que estan en camins reals, en les altres demés ciutats, viles i llocs no és ben entesa la llengua castellana de la gent comuna, $i$

44 Bellavista, J. (1989): «L'ús del català en les celebracions sacramentals a la diocesi de Barcelona. Estudi dels ordinaris o rituals barcelonins impresos del segle XVI al XIX», en Segon Congrés Internacional de la Llengua Catalana, VIII, 7, València, Institut de Filologia Valenciana, pp. 289-303. Aquí tenemos en cuenta los datos correspondientes a las ediciones del Ordinarium sacramentorum de 1501,1508 y 1532 y a la del Ordinarium seu rituale de 1620 . 
ningunes dones la usen (...), per ço me ha paregut ser de gloria de Deu vertir est llibre en les paraules mes planes i comunes de la llengua catalana per a que tota mena de gent puga d'ell aprofitar-se.» 4.5

La consecuencia inmediata de estos hechos fue la asimilación de la lengua catalana con todo aquello que se relacionaba con la vida cotidiana: las celebraciones dominicales, la vida, la muerte, la burla, la chanza, el mundo rural y la transmisión oral, y del español con lo culto, lo serio, lo solemne, lo urbano y la transmisión escrita. Se abrió así una profunda brecha diglósica de consecuencias multiseculares.

9. La situación descrita en los párrafos precedentes supuso la incorporación al catalán de numerosos castellanismos que afectaban fundamentalmente al léxico -alcansar, algo, alivio, arrastrar, assombrar, assunto, atrassar, averiguar, buscar, carga, carinyo, casar, conseguir, despedir, disfrutar, entregar, fulano, gastar, llanto, lograr, mando, modo, pago, puesto, quedar, queixar, recibo, resto, sombrero, terreno, varios - o al uso de algunos conectores -hasta, luego, pues-, algunos de los cuales acabaron imponiéndose y llegan hasta nuestros días ${ }^{46}$. Pero no podemos olvidar el efecto inverso.

Y no se trata solo de la presencia de algunos calcos semánticos o de los numerosos préstamos de vocabulario que tapizan de catalanismos los textos literarios escritos en castellano por autores catalanes y aragoneses, muchos de los cuales acabaron incorporándose al léxico común, sino de algo que me parece mucho más importante para la configuración del español moderno.

Por una parte, la documentación cancilleresca del siglo XV adaptó al castellano un número considerable de latinismos e italianismos, los mismos que se empleaban en los textos redactados en catalán. La extraordinaria riqueza del lenguaje administrativo de la Cancillería catalano-aragonesa, así como la abundante y frecuente correspondencia mantenida con la corte castellana durante el siglo XV y la posterior organización de la cancillería castellana en tiempos del rey Católico con intervención de los secretarios aragoneses, consagraron estas innovaciones léxicas. Por otra parte, en las cada vez más frecuentes obras de carácter técnico o científico se fijó una terminología precisa, en la que los latinismos y helenismos a menudo eran incorporados a partir de criterios lingüísticos emanados del catalán. ${ }^{47}$

45 Kempis, T. de: Imitació de Crist, traducción de P. Gil, Barcelona, 1621.

46 COLON, G. (1989): «El léxico catalán y el léxico español: su estudio contrastado», en El español y el catalán. juntos y en contraste, Barcelona, Ariel, pp. 59-84.

47 Las obras de MARTín Martínez De Ampies, tanto las de creación (Triunfo de Maria, Libro del Anticristo, Tratado de Roma) como las traducciones (Libro de Albeyteria, Viaje siquier 
Sin embargo, el escaso interés que han despertado estos textos se refleja claramente en la lexicografía etimológica: para numerosos términos, documentados repetidamente a lo largo del siglo XV en textos aragoneses ${ }^{48}$. se cita como primera documentación alguna obra literaria castellana de época muy posterior. Sirvan de ejemplo los siguientes términos de la primera letra del alfabeto considerados innovaciones del siglo XVI -abandonar, abastecer, abeto , abonado, abrasar, abrotano, absurdo, abultar, abuso, acetosa, acetosidad, acetoso, acoro, actitar, adaça, adjudicar, adjuncion, admirar, adramento, advocacion, adyacente, aereo, aficionar, agente, agressor, agrimonia, aguaça, aguamiel, aguanoso, alcançadura, alete, alimentacion, alimentar, alimento, aliño, alisar, aljez, ambiguo, amerar, amilanar, anales, aforismo, anual, anunciacion, apendicia, aperitivo, apetecer, apoca, aprehension, aquosidad, arcada, archiduque, argenteria, arrogancia, arronçar, artifice, ascender, asilo, asma, asserto, assessor, assistir, assumir, atestar, atestiguar, atropellar, azimo, auxilio-, del XVII —adorne, agencia, almodi, anuo, arrendador, arrendamiento, assentir, assimilar, atobar, atribucion, azalea-, del XVIII -archivero, asclitis, autumnal-e incluso del XIX —anilla, ademprio, amonita, anormal-La incorporación de esta documentación aragonesa como parte integrante del corpus lingüístico español necesariamente tendrá que ampliar nuestra visión de la evolución de la lengua.

10. Finalmente, no quisiera terminar sin aludir a otro factor directamente relacionado con la situación de bilingüismo de los sectores cultos catalanes a partir del siglo XVI. A pesar de la frecuente presencia de disculpas por escribir en «castellano no muy limado» ${ }^{49}$, es decir, por no escribir en «tan polido caste-

peregrinacion de la Tierra Sancta) constituyen un excelente ejemplo de esta incorporación. Véase Alvar, C. (1998): «Textos técnicos traducidos en Castilla», en G. Colón y L. Gimeno (eds.) Cultura i humanisme en les lletres hispàniques (s. XV-XVI), BSCC, LXXIV, pp. 235-255. Cf. también GaRCía MaCho, M.L. (1992): «Variedad léxica y cultismo en la lengua literaria del siglo XV», en R. Lorenzo (ed.), Actas XIX Cong. Intern. Ling. e Filol. Románicas, II, La Coruña, Fund. P. Barrié de la Maza, pp. 507-516.

48 Los datos pertenecen al estudio que estamos realizando en el Departamento de Filología Hispánica de la UB (PB95-0275 y PB98-1223) sobre el castellano del siglo XV en la Corona de Aragón y que recoge textos cancillerescos, jurídicos, médicos y narrativos, con un total de algo más de un millón de formas (GHCL: Diccionario General y Etimológico del castellano del siglo XV en la Corona de Aragón). Podrá verse una descripción más detallada de este proyecto de investigación en curso en las Actas del $V$ Congreso Internacional de Historia de la Lengua Española celebrado en Valencia, en febrero de 2000 (en prensa).

49 V.J. ANTIST (1575): La vida y historia del apostólico predicador sant Vincente Ferrer, valenciano de la orden de sancto Domingo, Valencia; edición de J.M. DE GARGANTA y V. ForCADA, Madrid, 1966, p. 236. 
llano cual se habla en Toledo» ${ }^{50}$, en la mayoría de los autores se refleja la idea de que las lenguas literarias pueden ser mejor dominadas por quienes no las tienen como lengua materna. Tema que arranca de las discusiones del Quatrocento italiano sobre la «cuestión de la lengua» ${ }^{51}$ y la forja de un «volgare illustre». Los autores catalanes se alinean claramente con la doctrina defendida por Pietro Bembo: la lengua literaria no tiene por qué basarse en la lengua hablada, de ahí que quienes no son hablantes naturales de una determinada lengua no deban quedar necesariamente excluidos de su uso literario. Esta es la teoría lingüística subyacente en la mayoría de prólogos de los escritores de la época, en los que se justifica su elección del español como lengua de expresión literaria.

Por ello, mientras en las producciones literarias en castellano del siglo XV la presencia del catalán o del aragonés afloraba constantemente, a partir del siglo XVI las obras escritas por autores catalanes ponen claramente de manifiesto ese carácter autónomo de la lengua literaria y, por consiguiente, su desvinculación de aquellos rasgos que pudiesen reflejar determinadas modalidades del nivel hablado. Mucho más fácil en su caso que en el de los hablantes nativos, porque para ellos la diferencia entre ambas modalidades no era solo una cuestión de registro, sino de actualización de sistemas distintos. Desde este punto de vista, era evidente que su uso de la lengua literaria, entendida como «lengua de ninguna parte», superaba al de los propios vernáculos. De ahí que Viciana ${ }^{52}$ pudiera afirmar con orgullo: «si no escrivo en toledano, a lo menos escrivo en todo castellano e harto mejor que no fueron escriptos los antiguos libros propios castellanos». La situación diglósica fue así asumida como un ideal lingüístico.

Pocos de ellos, posiblemente como consecuencia de esta actitud ante la lengua, consiguieron legarnos obras trascendentes. Pero su influencia es manifiesta en la labor de muchos de los teorizadores del siglo XVIII - Capmany, Mayans- que fueron, en buena medida, sus herederos, tanto geográfica como ideológicamente.

Y, en ciertos aspectos, su visión del carácter prevalente de esa lengua literaria atópica ha llegado hasta nosotros. De ahí el interés de un cambio de

91 M. DE VICIANA (1563): Crónica de la ínclita y coronada ciudad de Valencia; edición de S. García Martínez, Valencia, vol. III, p. 10.

sI Véase Vitale, M. (1978): La questione della lingua, Palermo. NADAL, J.M. (1989): «Problemes lingüístics en els segles XVI i XVII», en Segon Congrés Internacional de la Llengua Catalana, VIII, 7, València, Institut de Filologia Valenciana, pp. 62-64.

92 M. DE VICIANA, op. cit. Citado (y subrayado) por Fuster, J. (1989): «Català i castellà entre els valencians de la Il.lustració», en Segon Congrés Internacional de la Llengua Catalana. VIII, 7, València, Institut de Filologia Valenciana, pp. 19-30. 
rumbo en el estudio de la historia de la lengua que, enlazando de nuevo con las enseñanzas metodológicas de don Ramón Menéndez Pidal en sus Orígenes del español, incorpore las aportaciones de la sociolingüística para dar razón de la diversidad y de la variación lingüística a fin de permitirles emerger de ese bloque monolítico y homogéneo de la lengua literaria .

Se trata, por consiguiente, de no prescindir, a priori, de ningún registro. La cuestión está en enlazar los datos históricos con los sociolingüísticos y todos ellos con los textuales, de diversas procedencias. Y este es el gran tema: no tanto cómo es la lengua literaria de un determinado periodo sino, en todo caso, en qué medida y con qué alcance esta lengua literaria actúa como reguladora de la lengua «sin más», y en qué medida y con qué alcance cada una de las variantes contribuye a modelar la lengua literaria. 